\title{
LETTER
}

\section{Dialysis disequilibrium syndrome in neurointensive care unit: the benefit of intracranial pressure monitoring}

\author{
Pierre Esnault*, Guillaume Lacroix, Pierre-Julien Cungi, Erwan D'Aranda, Jean Cotte and Philippe Goutorbe
}

Dialysis disequilibrium syndrome (DDS) is a brain disease characterized by neurological symptoms due to cerebral edema after hemodialysis (HD). However, a direct measurement of intracranial pressure (ICP) rarely objectified this edema [1]. We report the case of a patient whose DDS was diagnosed by an increase of ICP.

A 51-year-old man was admitted for severe traumatic brain injury. At admission, an extradural hematoma was evacuated. After surgery, ICP monitoring guided the treatment. At day 4, toxic acute renal failure appeared. Fearing the occurrence of a DDS, we used continuous veno-venous hemofiltration $(\mathrm{CVVH})$, which allowed a gradual reduction in urea without an intracranial hypertension ( $\mathrm{ICH})$ episode. Later, after a resumption of diuresis, we stopped CVVH. At day 11, urea increased to $35.6 \mathrm{mmol} / \mathrm{L}$ and creatininemia to $452 \mu \mathrm{mol} / \mathrm{L}$. Serum sodium was $145 \mathrm{mmol} / \mathrm{L}$. Because the trauma had occurred several days before, we decided to perform HD. One hour after the start of HD, an ICH appeared (ICP = $37 \mathrm{~mm} \mathrm{Hg}$ ). Urea was $22.3 \mathrm{mmol} / \mathrm{L}$ and serum sodium was $144 \mathrm{mmol} / \mathrm{L}$ (unchanged). DDS was diagnosed. After HD was stopped, osmotherapy was administered, and neurosedation was increased, ICP returned to normal (Figure 1). Afterward, we successfully used CVVH

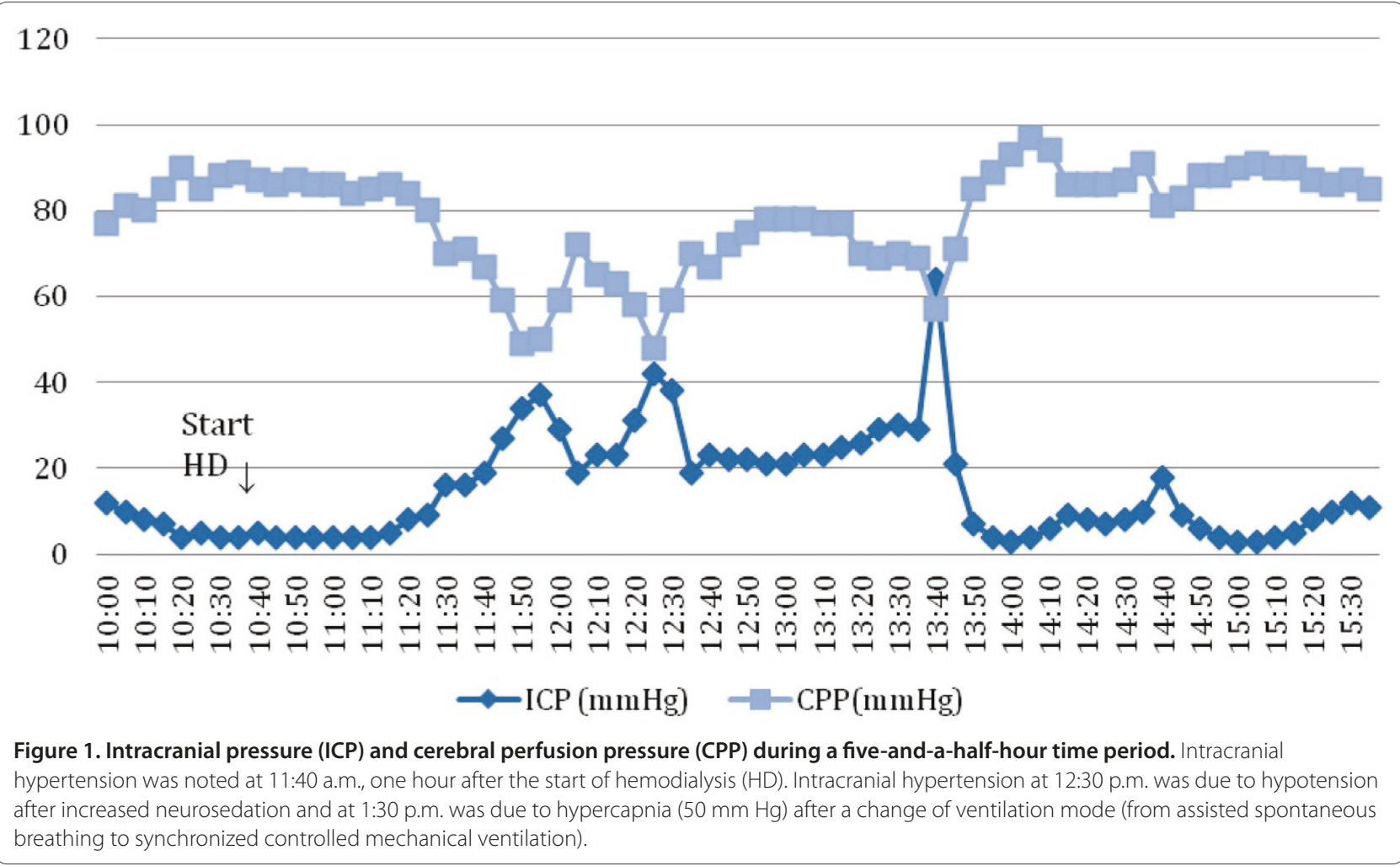


without a new episode of $\mathrm{ICH}$. At day 19, the patient was discharged and later made a full recovery.

DDS was first described in 1962 [2]. Symptoms due to cerebral edema vary from headache, nausea, and convulsion to coma. In our case, we detect DDS by ICP monitoring. Risk factors are first HD, severe uremia, age, pre-existing neurological disorders, and metabolic acidosis. A rapid clearing of small-sized molecules (such as urea) generated the symptoms. The main theory is the 'reverse urea effect', in which the shift of urea between brain intracellular space and plasma is not immediate but causes a brain intracellular space to interstitial osmotic gradient and leads to cerebral edema [3].

This case is didactic because, as we monitored the ICP, we saw the consequences of DDS on the brain. Treatments consist of a slow gentle start of HD, increasing dialysate sodium levels, and administration of osmotically active substances. We think that CVVH should be used to treat patients with risk factors, especially in the neurointensive care unit [4]. This technique allows gradual osmotic movement and minimizes the gradient between blood and cerebrospinal fluid.

In conclusion, in the intensive care unit, DDS should be considered at each alteration of consciousness during an
HD. We suggest that CVVH be used in predisposed patients to minimize the risk of DDS.

Abbreviations

CVH , continuous veno-venous hemofiltration; DDS, dialysis disequilibrium syndrome; HD, hemodialysis; ICH, intracranial hypertension; ICP, intracranial pressure.

\section{Competing interests}

The authors declare that they have no competing interests.

Published: 31 December 2012

\section{References}

1. Lin CM, Lin JW, Tsai JT, Ko CP, Hung KS, Hung CC, Su YK, Wei L, Chiu WT, Lee $L M$ : Intracranial pressure fluctuation during hemodialysis in renal failure patients with intracranial hemorrhage. Acta Neurochir Supp/ 2008, 101:141-144.

2. Kennedy AC, Linton AL, Eaton JC: Urea levels in cerebrospinal fluid after haemodialysis. Lancet 1962, 1:410-411.

3. Silver SM, DeSimone JA Jr., Smith DA, Sterns RH: Dialysis disequilibrium syndrome (DDS) in the rat: role of the 'reverse urea effect'. Kidney Int 1992, 42:161-166.

4. Dingli K, Arulkumaran N, Ball J: Dialysis disequilibrium syndrome in a neurosurgical patient: the role of continuous veno-venous hemofiltration. Minerva Anestesiologica 2012, 78:629.

doi:10.1186/cc11877

Cite this article as: Esnault $P$, et al:: Dialysis disequilibrium syndrome in neurointensive care unit: the benefit of intracranial pressure monitoring. Critical Care 2012, 16:472. 